\title{
JUGAR CON UN LENGUAJE VERBAL EN EL ESPACIO PLÁSTICO: XUL SOLAR, LA PINTURA Y LAS LENGUAS INVENTADAS
}

\author{
ANDREA ARMIJOS
}

Fecha de recepción: abril 2016

Fecha de aceptación: mayo 2016

\section{Resumen:}

A través del análisis de tres de sus obras, correspondientes a tres etapas diferentes de su vida artística, se pretende examinar la manera en que el artista argentino Xul Solar dinamizó los espacios artísticos para unirlos y trabajar en una intersección, especialmente entre la poesía/lenguaje y el arte plástico. Se contempla la activación de la palabra en un espacio pictórico, pero además como estas palabras y estas imágenes buscaban ser un correlato de los intereses más profundos del artista.

Palabras claves: Xul Solar, grafías, lenguaje, espacio plástico.

\begin{abstract}
:
This piece analyses the work of Argentinian artist Xul Solar in three of his works created in his different stages of artistic life. The purpose of this article is to explore the way in which the artist revitalized art spaces to connect them in a crossing between language/poetry and plastic art. It is seen how the use of the written word triggers a pictorial space, but also the way the words and the images sought to be connected to the artist's deepest interests.
\end{abstract}

Key Words: Xul Solar, graphs, language, plastic space.

\section{Autora:}

Andrea Armijos Echeverría, Quito 1996. Estudiante de tercer año de la carrera de Artes Liberales con especialización en Literatura, Historia del Arte e Historia en la Universidad San Francisco de Quito. 


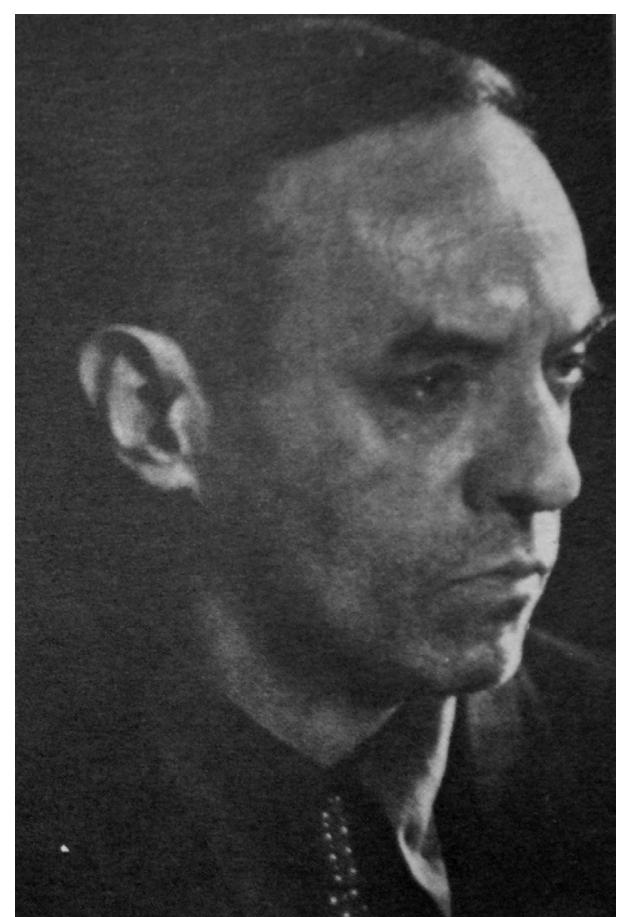

Xul Solar. Fotografía tomada de la colección de la revista "Pintores Argentinos del Siglo XX" Vol 1 to Vol 58 editado por Centro Editor de América Latina. Publicada en 1980 y 1981 en Buenos Aires, Argentina

“Surgió la luna sobre el río' se dice 'hlör u fang axaxaxas mlö’ o sea en su orden: hacia arriba (upward) detrás duradero-fluir luneció. (Xul Solar traduce con brevedad: upa tras perfluye lunó. Upward, behind the onstreaming it mooned.)" (Borges, $10)$,

escribe Jorge Luis Borges en su recordado cuento Tlön, Uqbar, Orbis Tertius, una historia de un universo inventado con sus propios valores, lenguajes, ideas, nociones del tiempo y el espacio, en general, una realidad paralela: Tlön, que es admirada por la humanidad terrestre por su peculiaridad. En esta historia Borges hace un guiño al artista argentino Óscar Alejandro Agustín Schulz Solari, mejor conocido como Xul Solar, un prolífico pintor, escritor y neologista que supo converger en su obra artística dos entidades de comunicación humana: el lenguaje plástico y el verbal.
Xul Solar nace en Buenos Aires, Argentina en 1887, ciudad en la que también fallecería setenta y cinco ańos después. Estudiante del mundo y de todas las disciplinas que este alberga, Xul Solar se destacó por ser un pensador que buscaba materializar en la creación artística los misterios más profundos del pensamiento humano, en los que se conjugaban la astrología, la religión, la historia, el mismo arte, la antropología, la poesía y la ciencia. Sobre él y su trabajo Borges escribió para el prólogo de una de sus exposiciones:

Sus pinturas son documentos del
mundo ultraterreno, del mundo
metafísico en que los dioses toman
las formas de la imaginación que los
sueńa. La apasionada arquitectura,
los colores felices, los muchos
pormenores circunstanciales, los
laberintos, los homúnculos y los
ángeles inolvidablemente definen este
arte delicado y monumental. (Borges,
1949)

Bajo el término "grafías plasti-útiles", Solar emprende el camino de sincretizar un lexicón textual con la imagen pictórica a través del color, la línea y la forma. Estas grafías pueden ser mejor explicadas como "textos plásticos escritos en neo-criollo [que] están constituidas por un conjunto de aforismos o 'piensos cortos' que Xul extrae de diversas fuentes así como doctrinas filosóficas" (Bendinger, 2004). De su enorme variedad de imágenes se pueden destacar tres de diferentes etapas en la vida artística de Xul Solar, obras en las que además son visibles los intentos de incorporar palabras extrañas al entorno gráfico. Esas tres pinturas son Imitá mi Pax de 1919, Juzgue de 1923, y Grafía de 1961.

Cronológicamente puede distinguirse una diferenciación de estilos en la obra de Xul Solar, estilos que van cambiando casi por décadas. En un principio abundan los motivos 
paisajísticos, siempre abstractos, pero con alguna reminiscencia a la figuración de lugares y rostros; poco a poco van mutando hacia la profundización filosófica a través del arte, hallamos más motivos astrológicos, orientales, motivos que evocan a la variedad de religiones mundiales. Hacia mediados de los cincuenta e inicios de los setentassu obra ya se asienta casi por completo en la estética de las grafías plásticas. Sin embargo, este ámbito de su creación sorprende por su conservación en el tiempo pues si bien al final componen casi la totalidad de las obras, en otras pinturas tan tempranas como de la década de 1910 es posible ver su inserción. Imitá mi Pax de 1919 nos introduce directamente a esa intersección creativa de la que Solar se alimenta constantemente: la producción lingüísticamente plástica. Si por algo, además de su obra pictórica, es conocido Xul Solar es por la invención de dos idiomas: la panlengua, y el neocriollo, sobre ellos una Amalia Fortabat sintetiza:

ideó el neocriollo, unido a la creación de la bandera de América Latina, evidenciaba y promulgaba la reivindicación de un arte latinoamericano. Paralelamente creó la panlengua. Idioma monosilábico, sin gramática que permitiría la comunicación universal. Una alternativa del esperanto, lengua utópica creada en el siglo XIX. (39).

El mismo título de esta obra, Imitá mi Pax está ya en neocriollo, una lengua que el artista deseaba crear a partir del español y el portugués, más un poco de inglés, alemán y francés, con el objetivo de unir idiomáticamente a América Latina en una sola lengua. El rostro cortado en dos partes emana colores y se desintegra en figuras geométricas, tiene cierta influencia cubista, la geometrización de las formas es esencial y el formato rectangular de la obra lo sobresalta. Pero en medio de esa configuración neo-cubista, aparecen algunas palabras regadas en el espacio: "Glamoveo", "Elvendemundo", "oh mi dueño", "abitao", "febril”, "imitá mi pax", "divulgação". Es sumamente difícil buscar una traducción, aun no existe un diccionario neocriollo, el mismo Solar decía "Soy maestro de una escritura que nadie lee todavía" (Tedín, 2005), pero justamente parece que su objetivo era que la imagen misteriosa, junto a las palabras que no son indescifrables, sino derivadas de idiomas conocidos, formarán juntas una narrativa, una historia entrecortada y de la que fluyera una idea profunda. En esta obra, al menos, los colores (algunos tan naturales como el marrón, mezclados con azules eléctricos, verdes y violetas) evocan la variedad, un rostro material y plástico que contiene los rostros de miles de personas más, las palabras son más dramáticas; sin embargo, nos hablan de vender mundos, de habitar un lugar, de un desasosiego, y el titulo converge todo esto: "Imita mi paz" en imperativo hacia el espectador.

Pero la introducción de las lenguas inventadas no es el único acercamiento a la palabra a través de la imagen pintada. En Juzgue de 1923 nuevamente las imágenes se simplifican a formas puramente geométricas que aunque escapan al contorno, están fluidamente delineadas por el contraste cromático entre el fondo (de un color cálido) y las formas superpuestas (de colores más brillantes), así, los rojos, azules y rosados saltan a la vista trazando tres figuras esenciales: dos masculinas y una femenina, un hombre parece arrodillarse frente a la mujer que se sienta en una especie de trono mientras al extremo derecho un verdugo sostiene por el hombro al hombre arrodillado. Pero aquí las palabras usadas por el artista no son neologismos, sino términos casi universales, cortos y fácilmente reconocibles, 
junto a la mujer aparece la palabra GEO, del griego y que significa Tierra, junto al hombre hay dos términos EGO y MAN entablando

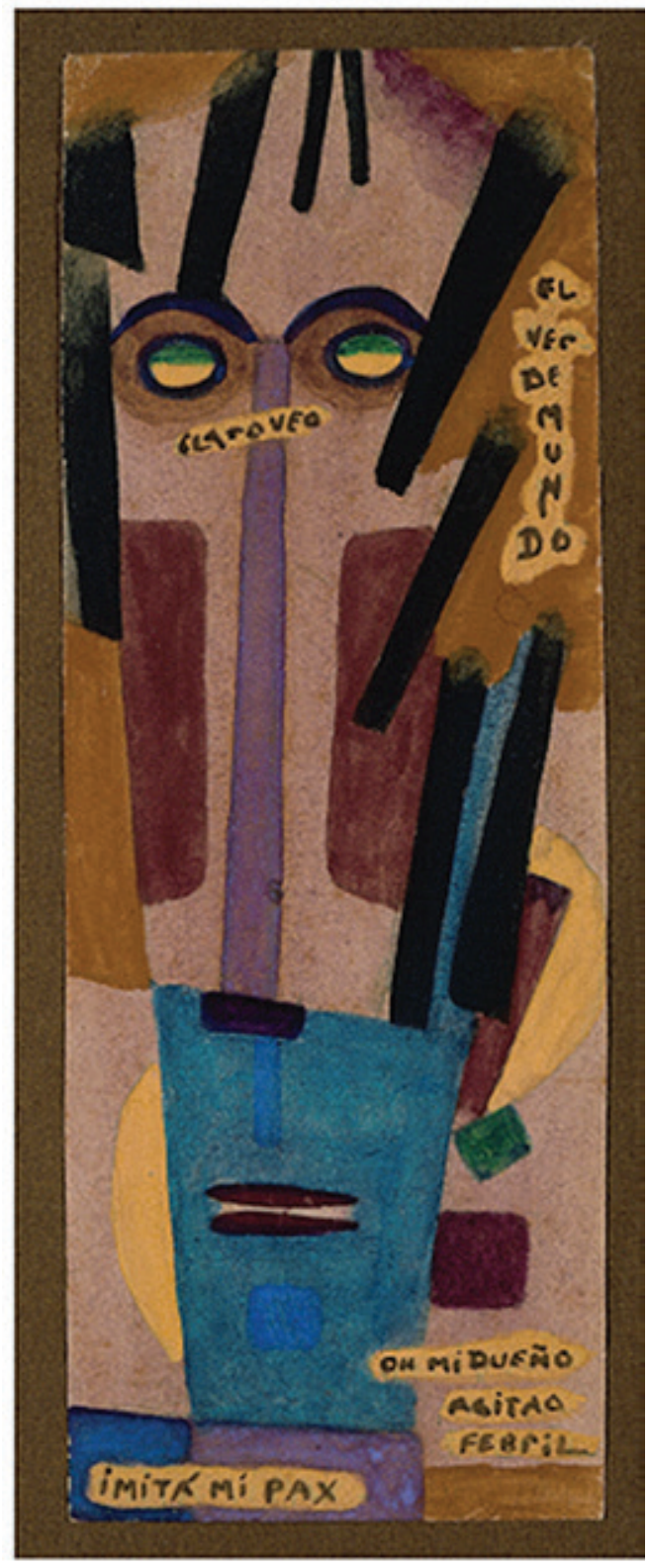

Imitá Mi Pax, 1919

una relación entre el hombre, traducción de la palabra inglesa "man", y un sentido de individualidad (ambiguo definitivamente) que viene del Yo que se traduce de la palabra latina EGO. De manera vertical como rompiendo el yugo entre un hombre y otro aparece la palabra en español PAZ, una de las palabras que también aparecía en Imitá mi Pax y que configura uno de los símbolos importantes de Xul Solar.
Finalmente en Grafía de 1961, hacia la última etapa de su producción artística, se retoma el curso que Xul tomaba con sus propios idiomas, tanto porque ya estaban más asentados como parte de su obra y también porque para esta temporada de su vida ya se habían editado algunos tomos de sus trabajos literarios que incluían panlengua y neocriollo. Grafía es justamente el producto más hibrido que puede resultar de los espacios lingüísticos y plásticos en la creación de Xul Solar, formando un "retratografía" el artista construye una figura o un rostro humano a través de símbolos panlingüisticos $\mathrm{y}$ algunos trazos astrales, pues este era otro de sus temas favoritos como se puede ver claramente resumido en su Pan árbol de 1954. Absolutamente todos los trazos que forman el rostro, a excepción de las líneas de la frente, son cada uno un símbolo imaginario que remonta un significado específico, pero adscrito a la funcionalidad de la panlengua, pues esta, como se ha mencionado antes, buscaba ser universal ( pan = todo, Universo etimológicamente). Resulta de hecho interesante anotar que la panlengua era

a más de eufónica, de funcionalidad taquigráfica. Los meollos gramaticales están en panlengua reducidos a esquemas representados simplemente por letras funcionando con la perfección que Xul Solar encontró en el orden irreprochable de la astrología. La $\mathrm{T}$, por ejemplo (letra que corresponde a Saturno), denota cantidad. Ti, poco; Tu, mucho; To, más; Te, menos. (Caron, 1969).

Aquella "funcionalidad taquigráfica" de la cual se habla sobre la panlengua está fácilmente 


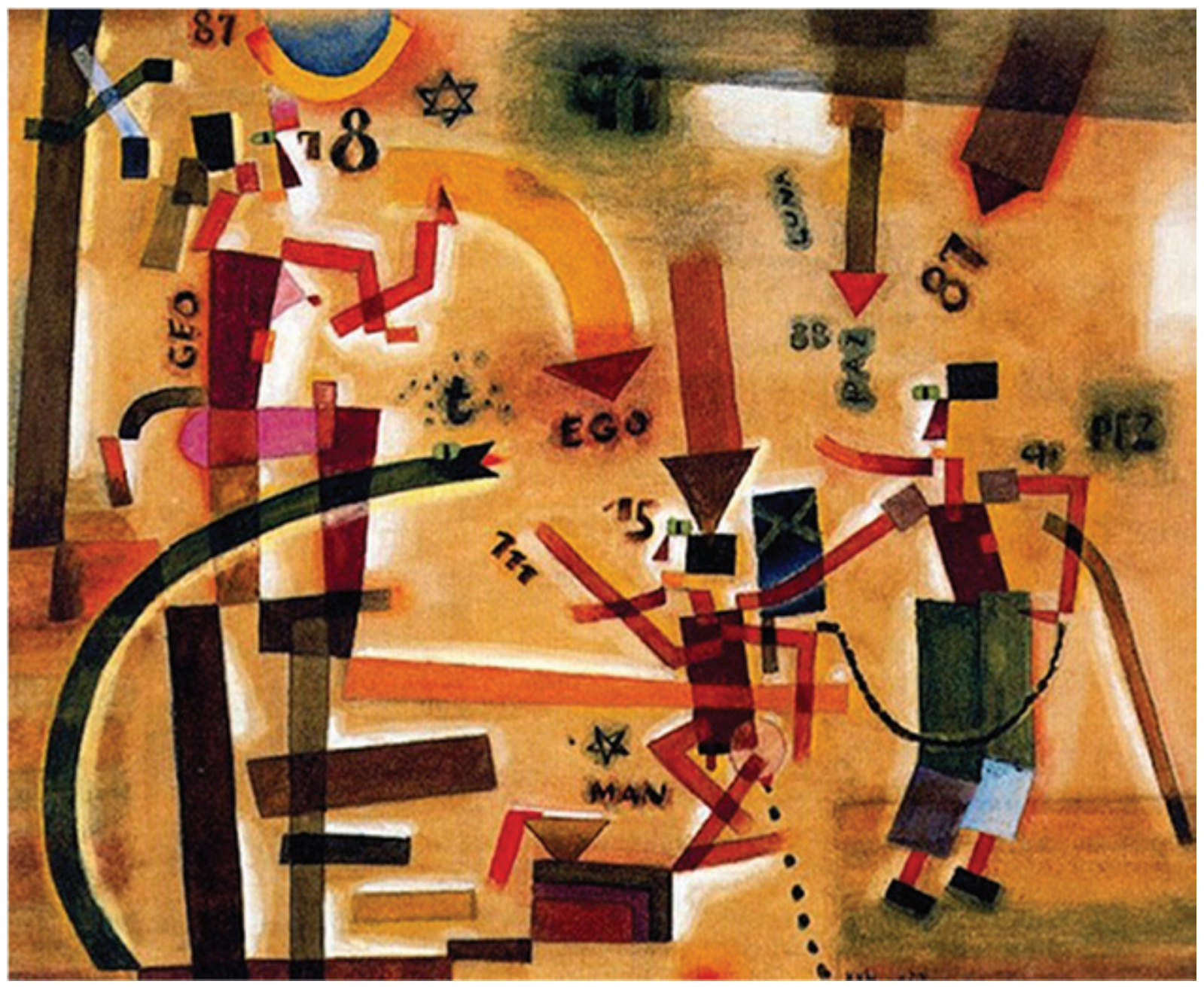

Juzgue, 1923

esquematizada en Grafía, los símbolos que forman los ojos, las cejas, las orejas y el contorno de las mejillas tienen esa naturaleza de trazo rápido y sintetizado. Pero a la vez, la paleta rica en colores hace que estos símbolos vueltos rasgos se hagan reconocibles, de esta manera los cabellos son todos azules, los contornos principales son marrones, los rasgos interiores de nariz y boca son naranjas y los ojos son verdes con pupilas azules. Una última conexión que puede desentrañarse del arte de Xul Solar y de su condición bipartita plástico-lingüística, incluso plástico-poética es que inspiró o fue parte estratégica de varias obras borgeanas, el cuento "La Suma", por ejemplo, parece construirle una narrativa al proceso de creación de Grafía a través de estas palabras:
Ante la cal de una pared que nada nos veda imaginar cómo infinita, un hombre se ha sentado y premedita trazar con rigurosa pincelada en la blanca pared el mundo entero: puertas, balanzas, tártaros, jacintos, ángeles, bibliotecas, laberintos, anclas, Uxmal, el infinito, el cero. (...) y, en el preciso instante de su muerte, descubre que esa vasta algarabía de líneas es la imagen de su cara. (Borges, 1985).

Más allá de las posibilidades interpretativas e hipotéticas que pueden derivarse de cualquier trabajo artístico por su naturaleza subjetiva $y$ emocional, la obra plástica de Xul Solar busca efectivamente ser la fuente de transmisión de un nuevo tipo de comunicación. La profundización del artista en una variedad de medios del 
conocimiento le permitió materializar "idiomas" que englobaran saberes distintos en un mismo espacio. De las grafías plastiútiles es esencial rescatar que fueron la forma que halló Xul Solar de comunicar estas ideas a través del lienzo, a través de la pintura y el color, tanto que el elemento semántico es apenas un añadido, probablemente porque es intrínseco a la figura.

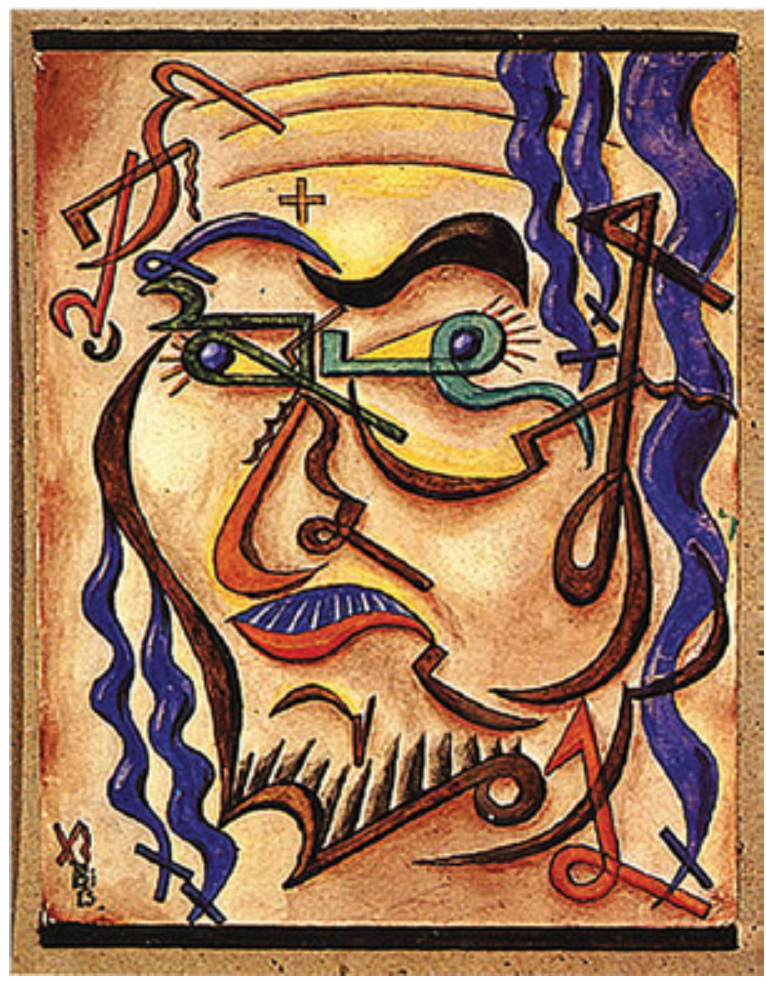

Grafia, 1961

Cuando se trae a colación la panlengua y el neocriollo como piezas del repertorio creativo de Solar, es posible hallar una línea de creación que siempre está en contacto con lo más universal vuelto detalle para ser compartido por el artista hacia la audiencia. Algo como el código de funcionamiento de una religión oriental, la filosofía mágica de lo astral, o los problemas sociales de desigualdad de género se transforman en rostros, figuras geométricas, escenas palpables y coloridas para concretizar lo que a simple vista parece etéreo. Las grafías repartidas en sus obras desde la década de 1910 son singulares porque magnifican el discurso filosófico detrás de la imagen, es como decirle al espectador que si aún con el trazo increíble y luminoso que ve en el lienzo no es suficiente para entrar en la obra, ese par de palabras regadas en el espacio pictórico le ayudan a incluirse en la composición. Estos "signos con cualidades semióticas" (Gallego Fernández) articulan lo que desde el inicio ha querido demostrarse con las obras de Solar: que el arte, un arte completo como el de Xul Solar, no compite entre sus ramas, sino que se complementa exquisitamente. La literatura que incubaba lenguas utópicas, como la pintura vanguardista que jugaba con los estilos y los formatos, fueron para este artista dos partes de un mismo tejido estético que mucho más allá de invocar al placer y al buen gusto como esperaría Hegel, llevaban a la reflexión y a la investigación, a tratar de descifrar las imágenes como a tratar de traducir las palabras.

\section{Bibliografía}

Bendinger, Ma. C. (2010). Xul Solar. Grafias plastiútiles pensiformes. Buenos Aires: Ed Jenik. Extraído el 06 de diciembre de 2015 desde http://coecos-dom.blogspot.com/2012/11/ grafias-plastiutiles-pensiformas-xul.html

Borges, J. (2005). La Suma en Los Conjurados. Buenos Aires: Emece Editores.

Borges, J. (2010). Tlön, Uqbar, Orbis Tertius en Ficciones. Bogotá: DeBolsillo.

Caron, C. (Agosto de 1969). Xul Solar, un habitante del misterio. Revista 2001. Buenos Aires, a. 2, n. 13, p. 54-59. 
Del Carmen Polo, G. (Febrero 2012).

Xul Solar, un referente de orden simbólico americanista. Doctorado Cooperativo de Investigación Artística. Granada: Universidad Nacional de Misiones. Extraído el 06 de diciembre de 2015 desde http://digibug.ugr.es/ bitstream/10481/35137/1/20981119.pdf

Fortabat, A. (2009). Biografía Xul Solar. La Colección: Arte argentino. Extraído el 05 de diciembre de 2015 desde http://www. coleccionfortabat.org.ar/educacion/guia_xul_ solar.pdf

Gallego Fernández, R. (2005). Contrapunto de montesy Yara: Xul Solar (Óscar Agustín Alejandro Schulz Solari). Museo Nacional Centro de Arte Reina Sofía. Extraído el 05 de diciembre de 2015 desde http://www.museoreinasofia.es/coleccion/ obra/contrapunto-montes-yara

Tedín, T. (2005). Xul Solar: visiones y revelaciones. Buenos Aires, Malba - Colección Constantini, p. 157-169. 